\title{
Effects of Chemical Modification on the Mechanical Properties of Calotropis Gigantea Fiber-reinforced Phenol Formaldehyde Biocomposites
}

\author{
Sekar SANJEEVI ${ }^{1}$, Athijayamani AYYANAR ${ }^{2}$, Ramanathan KALIMUTHU $^{3}$, \\ Sidhardhan SUSAIYAPPAN ${ }^{4}$
}

${ }^{1}$ Department of Mechanical Engineering, HIT, Coimbatore - 641 032, Tamilnadu, India

${ }^{2}$ Department of Mechanical Engineering, GCE, Bodinayakanur-625 582, Tamilnadu, India

${ }^{3}$ Department of Mechanical Engineering, ACCET, Karaikudi-630 004, Tamilnadu, India

${ }^{4}$ Department of Civil Engineering, GCE, Tirunelveli-627 007, Tamilnadu, India

crossref http://dx.doi.org/10.5755/j01.ms.26.3.17749

Received 13 March 2017; accepted 23 August 2017

\begin{abstract}
In this paper, the effects of three different chemical treatments on the mechanical properties of Phenol Formaldehyde (PF) composites reinforced with the Calotropis Gigantea Fibers (CGFs) were investigated based on the fiber content of the fibers. Composites were prepared by the untreated and treated fibers using the hand lay up technique and their mechanical properties were evaluated and compared. The results revealed that the composites show the greater mechanical properties at $40 \mathrm{wt} . \%$ for the untreated condition. Composites prepared with alkali treated fibers show the better mechanical properties as compared with the other treated fiber composites.

Keywords: Calotropis Gigantea fiber, phenol formaldehyde, chemical modification, mechanical properties.
\end{abstract}

\section{INTRODUCTION}

Recently, the focus of the material engineer and researchers is towards on the environmental alertness and sustainable product development. They were concentrating on the development of natural cellulose fibers as reinforcing agent in polymer composite manufacturing to meet the above requirements [1,2]. Natural fibers were interesting and attractive over the synthetic fibers in polymer composites due to their low density, light weight, inexpensive, abundant availability, high specific strength and stiffness, non-abrasive nature, minimal health hazards, biodegradability, and renewability [3]. These fibers were reinforced with both the thermoplastics and thermosets resin matrices. Among these, phenol formaldehyde resin matrix is reinforced by several types of natural cellulose fibers to improve its properties. Sreekala et al. [4] studied the influence of fiber surface modifications on the mechanical performance of oil palm fiber-reinforced phenol formaldehyde composites and found that composites having the modified fibers show the excellent impact resistance. Many numbers of researchers have been carried out the performance study on the natural cellulose fiber-reinforced phenol formaldehyde composites: grass/phenol formaldehyde [5], Wereca /roselle/phenol formaldehyde [6], sisal/phenol formaldehyde [7], Wereca/phenol formaldehyde [8], banana/phenol formaldehyde [9], Grewia optiva/phenol formaldehyde [10], and Calotropis Gigantea/phenol formaldehyde [11]. All the above research works report that the phenol formaldehyde composites can be prepared using the natural cellulose fibers as reinforcing agents with the improved properties.

\footnotetext{
* Corresponding author. Tel.: +91-9865906160; fax: +91-04546-282550.

E-mail address: athimania@gmail.com (A. Athijayamani)
}

Natural cellulose fibers as reinforcements have some disadvantages, even though they have many attractive advantages. The main disadvantages were higher moisture absorption tendency, low impact strength, and less compatibility with the polymer matrix. The hydrophilic nature of the natural fibers creates adhesion problem with the polymer matrix (hydrophobic nature). Due to the incompatibility of the fibers with the matrix, the aggregates were formed within the composites, which exhibit the poor resistance to moisture. It leads to higher water uptake resulting in poor dimensional stability and mechanical properties of the composites [12].

To solve the above mentioned problems, the fiber or the matrix or both the fiber and the matrix may be modified by physical and chemical methods. The chemical methods were satisfactorily used by many researchers to improve the hydrophobic nature of the fibers, interfacial bonding between the fiber and the matrix, wettability, and surface roughness, leading to the improvement of mechanical properties of the composites [13]. Among the various chemical treatments, alkali treatment, benzoylation treatment, and esterification treatment were extensively used by the number of material researchers [14]. However, very limited investigation is carried out on the chemical modification of Calotropis Gigantea fiber as reinforcing agent for phenol formaldehyde composites. This research paper has been prepared, with an objective to investigate the potential of Calotropis Gigantea fiber as a reinforcing agent in polymer matrix composites and to investigate its effect at untreated and treated condition on the mechanical properties of the resulting composites. The surface of the fibers is modified by alkali treatment, benzoylation treatment, and esterification treatment and used as reinforcing materials for the phenol formaldehyde resin matrix. 


\section{EXPERIMENTAL DETAILS}

\subsection{Materials}

The CGFs having the diameter range of $0.11-0.83 \mathrm{~mm}$, the length range of $0.2-0.6 \mathrm{~m}$, the density of $0.56 \mathrm{~g} / \mathrm{cm}^{3}$, and ultimate stress range of $124-381 \mathrm{MPa}$ were used as reinforcing material for a resole type phenol formaldehyde resin matrix. The CGFs had the cellulose of $57 \%$, hemicellulose of $21 \%$, lignin of $13 \%$, and alkali soluble substances of $9 \%$. The PF resin having the density of $1.3 \mathrm{~g} / \mathrm{cm}^{3}$ and specific gravity of $1.12-1.16$ was used with the cross-linking agent and acidic catalyst in the present study. The CGFs were extracted from the stem of the CG plant manually and cut into the length of $9 \mathrm{~mm}$ for the use as a reinforcing agent for the PF resin matrix. All chemical agents were purchased from POOJA chemicals, Madurai, Tamilnadu, India.

\subsection{Chemical modifications of fiber}

Alkali treatment of natural cellulose fibers changes the orientation of highly packed crystalline cellulose order and forms a rough surface by swelling the fiber cell wall which provides more access to penetration of the polymer matrix. The raw CGFs were initially extracted from the stem of the Calotropis Gigantea plant and cleaned manually using metal wire brush. The cleaned fibers were immersed in $10 \% \mathrm{NaOH}$ solution for 1 hour at room temperature. After that, the fibers were taken over from alkali solution and thoroughly washed with distilled water and subsequently neutralized with $2 / 3$ drops of hydrochloric acid solution. Finally, the treated fibers were dried in sunlight for 24 hours. The following reaction takes place as a result of alkali treatment of the fibers [15]:

Fiber-OH+NaOH $\rightarrow$ Fiber-O-Na+ $\mathrm{H}_{2} \mathrm{O}$.

In the benzoylation treatment, the benzoyl chloride is used to decrease the hydrophilicity of the cellulose fibers and improve adhesion strength between the fiber and the matrix, thus increasing the strength of the composite. For benzoylation treatment, the fibers were initially pre-treated with $18 \%$ of $\mathrm{NaOH}$ for 30 minutes to activate the hydroxyl groups and then, the fibers were filtered and washed in tap water. The fibers were designated as pretreated fibers and then, they were immersed at $10 \% \mathrm{NaOH}$ solution and agitated with benzoyl chloride. After sometimes, the fibers were filtered and again washed thoroughly with the tap water. Finally, the fibers were pendant in ethanol for 1 hour to remove the benzyl chloride and washed dried in sunlight for 48 hours. The reaction between the fiber and benzoyl chloride is shown as follows [16]:

Fiber-OH+NaOH $\rightarrow$ Fiber-O-Na+ $\mathrm{H}_{2} \mathrm{O}$;

Fiber-O-Na+ $\mathrm{C}_{6} \mathrm{H}_{5} \mathrm{CH}_{2} \mathrm{Cl} \rightarrow$ Fiber-O- $\mathrm{C}_{6} \mathrm{H}_{5} \mathrm{CH}_{2}+\mathrm{NaCl}$.

The esterification method is also known as acetylation treatment for the modifying the surface of natural cellulose fibers. The fibers were acetylated with glacial acetic acid, which reacts with the hydroxyl groups of the fibers and swells the fiber cell wall. It results in decreasing the hydrophilic nature of the fiber which leads to the improvement in dimensional stability and enhancement of mechanical properties of resulting composites. For esterification treatment, initially, the fibers were pretreated with $18 \%$ of $\mathrm{NaOH}$ for 1 hour at room temperature. The alkali treated fibers were immersed in glacial acetic acid for 1 hour at room temperature. Then, the fibers were again immersed in acetic anhydride containing the two drops of sulfuric acid for 30 minutes. The reaction of acetic anhydride with the acetylated fiber is shown as [17].

Fiber- $\mathrm{OH}+\mathrm{CH}_{3}-\mathrm{C}(=\mathrm{O})-\mathrm{O}-\mathrm{C}(=\mathrm{O})-\mathrm{CH}_{3} \rightarrow$ Fiber- $\mathrm{OCOCH}_{3}+\mathrm{CH}_{3} \mathrm{COOH}$.

\subsection{Fabrication of composites}

Composite plates were prepared using hand lay-up technique by a mould with the size of $150 \times 150 \times 3 \mathrm{~mm}$ [18]. First, poly vinyl alcohol as a releasing agent was applied on the inner side of the mould to ensure easy removal of cured composite plates. Then, the fibers in a calculated amount were mixed with PF resin and stirred by a mechanical stirrer for $30 \mathrm{~min}$. After that, the crosslinking agent (divinylbenzene) and acidic catalyst (hydrochloric acid) were added with the fibers and PF resin mixture with ratio of $2: 1.5: 100$ and again stirred by a mechanical stirrer for $15 \mathrm{~min}$. The mixture was poured into the mould and pressed using a laboratory hot press. Finally, the mould box containing the composite plate was allowed to cure at room temperature under atmospheric pressure for 48 hours.

\subsection{Characterization of composite specimens}

For mechanical tests, composite specimens with the size of $150 \times 20 \times 3 \mathrm{~mm}$ were cut from the prepared composite plates. Tensile tests were performed according to ASTM D638-10 on an FIE (Fuel Instruments \& Engineers) universal testing machine (model: UTE-10) (18) at a crosshead speed of $2 \mathrm{~mm} / \mathrm{min}$ in room temperature and humidity of $50 \%$. Flexural tests were also conducted on the same FIE universal testing machine (model: UTE-10) according to ASTM D790-10 at a crosshead speed of $2 \mathrm{~mm} / \mathrm{min}$ in room temperature and humidity of $50 \%$. Izod impact tests were conducted on TO (Tinius Olsen) impact tester (model: IT503\&504) according to ISO180:2000 at room temperature and humidity of $50 \%$.

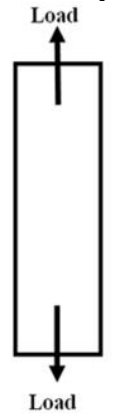

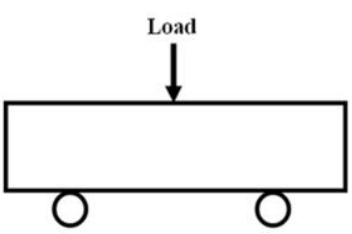

b

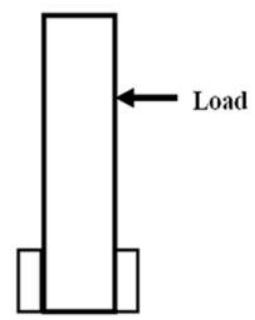

Fig. 1. Schematic diagram of the producers of the used equipments for the investigations: $a$-tensile test; $\mathrm{b}$-flexural (three point bending) test; $\mathrm{c}$-impact test 
The test procedures for the determination of tensile, flexural and impact property values using a universal testing machine and impact tester were given in Fig. 1.

\section{RESULTS AND DISCUSSION}

\subsection{Mechanical properties of composites at untreated condition}

The variation of tensile properties of $\mathrm{CGF} / \mathrm{PF}$ composites based on the fiber content is given in Fig. 2. It can be observed that the composites reach the tensile property values of the neat resin sample at $20 \mathrm{wt} . \%$. The percentage of fiber content below the critical fiber content cannot enhance the tensile properties of composites. It may be due to the poor dispersion of the fibers into the polymer resin matrix which results in improper interfacial adhesion between the fiber and the matrix. The tensile properties of composites were reduced due to this improper adhesion [19]. The tensile modulus of the PF resin matrix was enhanced by the addition of the CGFs. The tensile property values increase with the increase of the fiber content up to 40 wt. $\%$ and then decreased. This may be due to the congregation of fibers, which takes place instead of fiber dispersion within the composite. Due to this, the PF resin matrix cannot wet the fibers properly because the entering of PF resin matrix between the fibers is restricted. Therefore, the resulting composites were in brittle nature, which leads to the quick failure of composite [19]. The maximum tensile modulus values were obtained at $40 \mathrm{wt} . \%$ of fiber composites. The highest tensile strength is obtained at $40 \mathrm{wt} . \%$, which is $41.7 \%$ higher than the neat resin sample. The highest tensile modulus value is also observed at $40 \mathrm{wt} . \%$, which is $4.85 \%$ higher than the untreated fiber composites at $40 \mathrm{wt} . \%$. The tensile modulus values increased with the increase of the fiber content up to $40 \mathrm{wt} . \%$, after that, it decreased.

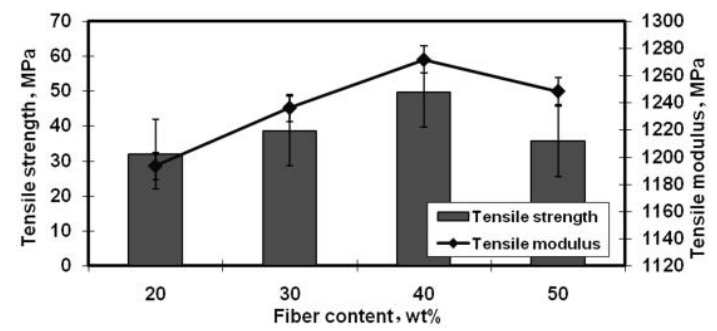

Fig. 2. Variations of the tensile properties of CGF/PF based on the fiber content at untreated condition

Fig. 3 shows the variations of the flexural properties of CGF/PF composites based on the fiber content. The same trend like in the tensile properties is observed in the results of the flexural properties. The flexural property values reach the property values of the neat resin sample at $20 \mathrm{wt} . \%$. It may be due the starting of the proper distribution of the fibers within the composites [20]. The flexural modulus values increased with the increase of the fiber content up to $40 \mathrm{wt} . \%$ and then dropped. The proper reason is that the wettability in the composites having the higher fiber content is reduced due to the insufficient polymer resin matrix. Therefore, composites fail under low load condition [20]. Composite having the fiber content of $40 \mathrm{wt}$ \% shows the highest flexural modulus value which is
$39.8 \%$ higher than that of the $20 \mathrm{wt} . \%$ composite. The maximum flexural modulus value is obtained at $40 \mathrm{wt} . \%$, which shows the $5.4 \%$ of improvement as compared to 20 wt.\% fiber composite.

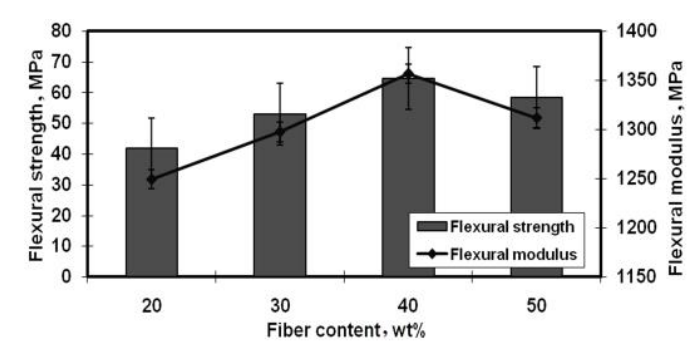

Fig. 3. Variations of the flexural properties of CGF/PF based on the fiber content at untreated condition

The impact strength values of CGF/PF composites at untreated condition based on the fiber content were given in Fig. 4. The impact strength values reach the neat resin sample values at $20 \mathrm{wt} . \%$ of fiber content. The impact strength values were also increased up to $40 \mathrm{wt} . \%$ and then dropped. This reduction in impact strength may be due to the weak interfacial adhesion between the fiber and the matrix. This weak interfacial adhesion was formed by the restriction of entering the resin matrix in the fiber rich area [21]. The maximum impact strength value was observed at 40 wt.\%. An improvement of $35.8 \%$ was obtained at 40 wt.\% composite when compared with the neat resin sample.

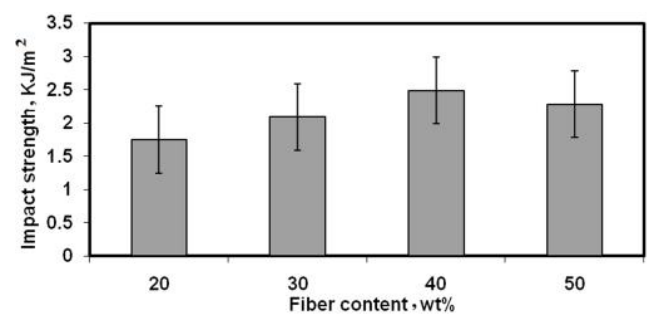

Fig. 4. Variations of the impact strength of CGF/PF based on the fiber content at untreated condition

From the above results, the composites having the fiber content of $40 \mathrm{wt} \%$ give the maximum mechanical properties. Therefore, it is proved that the $40 \mathrm{wt} . \%$ of fiber content is an optimum fiber content to obtain the better combination of mechanical properties in the $\mathrm{CGF} / \mathrm{PF}$ composites.

\subsection{Mechanical properties of composites at treated condition}

To study the effects of chemical modification of the CGFs on the mechanical properties of PF resin matrix, 40 wt. $\%$ of composites were taken both the untreated and treated conditions. The treated fibers at $40 \mathrm{wt} . \%$ were used to prepare the treated fiber composites and their mechanical properties were compared with the untreated fiber composites at $40 \mathrm{wt} \%$.

Fig. 5 shows the tensile strength of CGF/PF composite having the fiber content of $40 \mathrm{wt} \%$. It can be seen that the tensile strength of the composites increased with the addition of the treated fibers. All the treatments show greater tensile strength than that of the untreated fiber composite. The maximum tensile strength is obtained at 
alkali treatment as compared to the other treatments. Generally, natural cellulose fibers consist of several elementary fibers associated with cellulose, hemicellulose, pectin, lignin, etc. From these elements, the unwanted elements were removed by the chemical modification of the fibers, which leads to the strong interfacial bonding, resulting in improved mechanical properties of composites [22]. The increase in tensile properties of alkali treated fiber composites could be due to the increased interfacial adhesion between the fiber and the matrix after treatment [22]. On the other hand, the tensile modulus value is also higher for alkali treated composite as compared with the other treatments. The tensile modulus of the composites, treated by the benzoylation and esterification methods is lower than the untreated fiber composites.

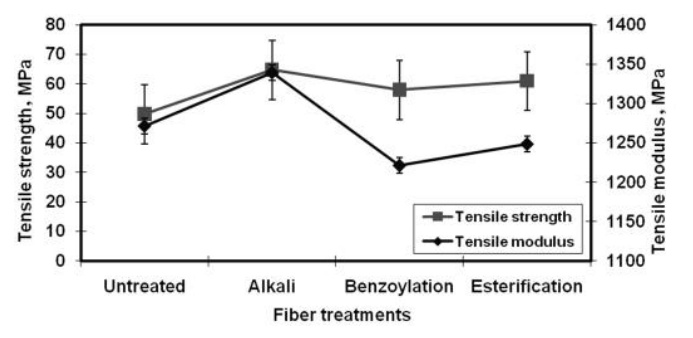

Fig. 5. Variations of the tensile properties of CGF/PF based on the fiber treatments

The variations of the flexural properties of the CGF/PF composites having the fiber content of $40 \mathrm{wt} \%$ were presented in Fig. 6. It is clear that here also alkali treatment gives the maximum flexural strength as compared to the other treatment methods. It may be due to the proper removal of unwanted elements from the fiber surface as compwered to the other treatments. The flexural strength and modulus of the treated fiber composites were greater than the untreated fiber composites. When compwered with benzoylation and esterification treatment methods, the esterification treatment methods show the better flexural properties.

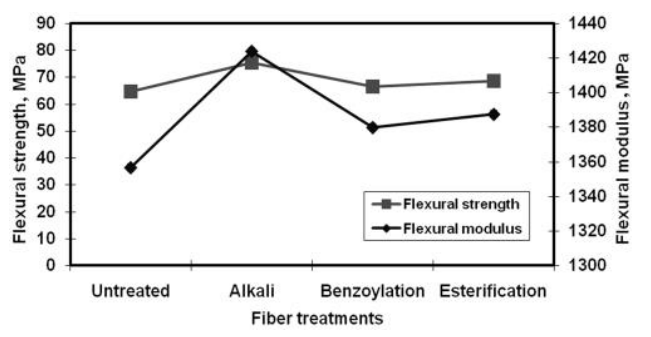

Fig. 6. Variations of the flexural properties of CGF/PF based on the fiber treatments

Fig. 7 shows the impact strength values of the CGF/PF composites having the fiber content of $40 \mathrm{wt} . \%$. It is observed that the maximum impact strength value is obtained at the alkali treated fiber composites. Alkali treatment makes the fiber surface coarser, which leads to strong interfacial bonding between the fiber and the matrix. Alkali treatment is also breaking the fiber bundles in to smaller fibers (fibrillation). Due to the fibrillation, the diameter of the fiber is reduced (aspect ratio of the fiber increases) which leads to the effective surface area available for wetting of the resin matrix material. This results in obtaining the improved mechanical properties of the composites [23]. The impact strength of esterification treated fiber composite show the better impact strength than that of benzoylation treated fiber composites.

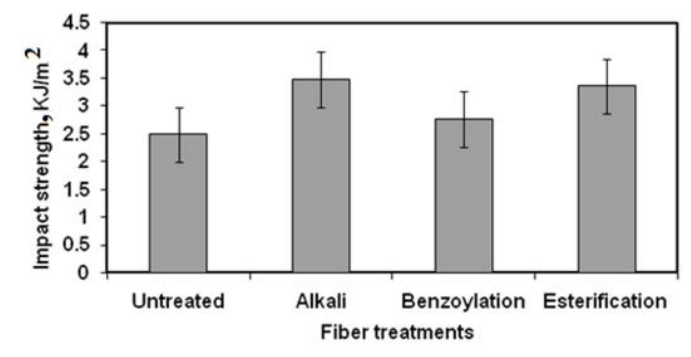

Fig. 7. Variations of the impact strength of CGF/PF based on the fiber treatments

\section{CONCLUSIONS}

The effect of addition of chemically modified Calotropis Gigantea fibers on the mechanical properties of the phenol formaldehyde composites was investigated and compared with the untreated fiber composite. Composites having the fiber content of $40 \mathrm{wt} . \%$ show the maximum level of mechanical properties as compared to the other fiber content composites at untreated condition. In the case of chemical modification of the fibers, the properties of composites prepared by the treated (using all the fiber treatment methods) fibers were better than the untreated fiber composites. However, composites prepared by the alkali treated fiber composites show the greater mechanical properties as compared to the other treatment methods. Finally, this study confirmed that Calotropis Gigantea fiber-reinforced phenol formaldehyde composites could be successfully prepared with good combination of mechanical properties by alkali treatment. Therefore, the production of natural fiber-reinforced polymer composites with desired mechanical properties were possible only through careful selection and design of composites.

\section{REFERENCES}

1. Dweib, M.A., Hu, B., O'Donnell, A., Shenton, H.W., Wool, R.P. All Natural Composite Sandwich Beams for Structural Applications Composite Structures 63 2004: pp. $147-157$.

https://doi.org/10.1016/S0263-8223(03)00143-0

2. Graupner, N., Herrmann, A.S., Müssig, J. Natural and Man-Made Cellulose Fibre-Reinforced Poly (Lactic Acid) (PLA) Composites: An Overview About Mechanical Characteristics and Application Wereas Composites Part A 40 2009: pp. 810-821.

https://doi.org/10.1016/j.compositesa.2009.04.003

3. Mwaikambo, L. Review of the History, Properties and Application of Plant Fibres African Journal of Science and Technology 7 (2) 2006: pp. 121-133.

4. Sreekala, M.S., Kumaran, M.G., Joseph, S., Jacob, M., Thomas, S. Oil Palm Fibre Reinforced Phenol Formaldehyde Composites: Influence of Fibre Surface Modifications on the Mechanical Performance Applied Composite Materials 7 2000: pp. 295-329. https://doi.org/10.1023/A:1026534006291

5. De, D., Adhikari, B., De, D. Grass Fiber Reinforced Phenol Formaldehyde Resin Composite: Preparation, Characterization and Evaluation of Properties of Composite 
Polymers for Advanced Technologies 18 (1) 2007: pp. $72-81$.

https://doi.org/10.1002/pat.854

6. Athijayamani, A., Chrispin Das, M., Sekar, S., Ramanathan, K. Mechanical Properties of Phenol Formaldehyde Hybrid Composites Reinforced with Natural Cellulose Fibers BioResources 12 (1) 2017: pp. $1960-1967$.

https://doi.org/10.15376/biores.12.1.1960-1967

7. Maya, M.G., George, S.C., Jose, T., Sreekala, M.S., Thomas, S. Mechanical Properties of Short Sisal Fibre Reinforced Phenol Formaldehyde Eco-Friendly Composites Polymers from Renewable Resources 8 (1) 2017: pp. $27-42$.

https://doi.org/10.1177/204124791700800103

8. Swamy, R.P.,

Mohan Kumar, G.C., Vrushabhendrappa, Y., Joseph, V. Study of WerecaReinforced Phenol Formaldehyde Composites Journal of Reinforced Plastics and Composites 23 (13) 2004: pp. $1373-1382$.

9. Joseph, A., Baby, B., Thomas, A.B., Sreyas Krishnan, S. Preparation and Characterization of Banana Reinforced Phenol Formaldehyde Composite European Journal of Advances in Engineering and Technology 2 (5) 2015: pp. $85-90$.

10. Singha, A.S., Thakur, V.K. Synthesis and Characterization of Grewia Optiva Fiber-reinforced pfBased Composites International Journal of Polymeric Materials and Polymeric Biomaterials 57 (12) 2008: pp. 1059-1074.

https://doi.org/10.1080/00914030802257800

11. Athijayamani, A., Sekar, S., Sidhardhan, S., Ramanathan, K. Mechanical Properties of Randomly Oriented Calotropis Gigantea Fiber-reinforced Phenol Formaldehyde Biocomposites Journal of Advances in Chemistry 13 (11) 2017: pp. 6043-6050. https://doi.org/10.24297/jac.v13i11.5910

12. John, M.J., Francis, B., Varughese, K.T., Thomas, S. Effect of Chemical Modification on Properties of Hybrid Fiber Biocomposites Composites Part A: Applied Science and Manufacturing 39 (2) 2008: pp. $352-363$. https://doi.org/10.1016/j.compositesa.2007.10.002

13. Holbery, J., Houston, D. Natural-fiber-reinforced Polymer Composites in Automotive Applications Journal of the Minerals, Metals and Materials Society 58 2006: pp. $80-86$. https://doi.org/10.1007/s11837-006-0234-2

14. Mwaikambo, L.Y., Ansell, M.P. Chemical Modification of Hemp, Sisal, Jute, and Kapok Fibers by Alkalization Journal of Applied Polymer Science 84 2002: pp. $2222-2234$. https://doi.org/10.1002/app.10460

15. Li, X., Tabil, L.G., Panigrahi, S. Chemical Treatments of Natural Fiber for Use in Natural Fiber-Reinforced Composites: A Review Journal of Polymers and the Environment 15 2007: pp. 25-33. https://doi.org/10.1007/s10924-006-0042-3

16. Rowell, R.M., Han, J.S., Rowell, J.S. Characterization and Factors Effecting Fiber Properties Natural Polymers and Agrofibers Composites 2000: pp. 115-134.

17. Rong, M.Z., Zhang, M.Q., Liu, Y., Yang, G.C., Zeng, H.M. The Effect of Fiber Treatment on the Mechanical Properties of Unidirectional Sisal-Reinforced Epoxy Composites Composite Sciences and Technology 61 2001: pp. $1437-1447$. https://doi.org/10.1016/S0266-3538(01)00046-X

18. Athijayamani, A., Stalin, B., Sidhardhan, S., Alavudeen, A. Mechanical Properties of Unidirectional Aligned Bagasse Fibers/Vinyl Ester Composite Journal of Polymer Engineering 36 (2) 2015: pp. 157-163. https://doi.org/10.1515/polyeng-2014-0325

19. Rashed, H.M.M.A., Islam, M.A., Rizvi, F.B. Effects of Process Parameters on Tensile Strength of Jute Fiber Reinforced Thermoplastic Composites Journal of Naval Architecture and Marine Engineering 3 2006: pp. 1-6. https://doi.org/10.3329/jname.v3i1.923

20. Romanzini, D., Lavoratti, A., $\quad$ Ornaghi Jr, H.L., Amico, S.C., Zattera, A.J. Influence of Fiber Content on the Mechanical and Dynamic Mechanical Properties of Glass/Ramie Polymer Composites Materials and Design 47 2013: pp. 9-15. https://doi.org/10.1016/j.matdes.2012.12.029

21. Salman, S.D., Leman, Z., Sultan, M.T.H., Ishak, M.R., Cardona, F. Influence of Fiber Content on Mechanical and Morphological Properties of Woven Kenaf Reinforced Pvb Film Produced Using a Hot Press Technique International Journal of Polymer Science 2016 2016: pp. 1-11. https://doi.org/10.1155/2016/7828451

22. Goud, G., Rao, R.N. Effect of Fibre Content and Alkali Treatment on Mechanical Properties of Roystonea RegiaReinforced Epoxy Partially Biodegradable Composites Bulletin of Materials Science $34(7)$ 2011: pp. $1575-1581$. https://doi.org/10.1007/s12034-011-0361-4

23. Li, Y., Mai, Y., Ye, L. Sisal Fiber and its Composites: A Review Of Recent Developments Composite Science and Technology 60 2000: pp. 2037-2055. https://doi.org/10.1016/S0266-3538(00)00101-9 